\title{
https://doi.org/10.48009/1_iis_2005_339-345 \\ IDENTIFYING COMPETENCIES FOR THE IT WORKFORCE: A QUANTITATIVE STUDY
}

\author{
Paul J. Kovacs, Robert Morris University, kovacs@rmu.edu \\ Gary A. Davis, Robert Morris University, davis@rmu.edu \\ Donald J. Caputo, Robert Morris University, caputo@rmu.edu \\ John C. Turchek, Robert Morris University, turchek@rmu.edu
}

\begin{abstract}
As a historical study of professions would reveal, there is a strong relationship between any profession and the university complex. This is especially true with the rapid growth of the information technology (IT) profession and the academic programs in computing offered by colleges and universities. The dynamic growth of the IT profession provides an ongoing undertaking for IT educators who are responsible for preparing both entry-level and experienced IT professionals for the workforce. This paper reports survey results of IT professionals' perceptions of what are the needed IT competencies for both entry level and established IT professionals. Specific IT competencies are derived through questionnaire responses. The tabulated results identify those competencies considered either critical, useable, or of no importance to the curricular offerings in IT related programs in higher education.
\end{abstract}

Keywords: IT competencies, IT skills, IT knowledge areas, information systems curriculum development, relationships of academe and the professions

\section{INTRODUCTION}

As the study of the history of the professions would reveal, there is a strong relationship between any profession and the university complex. This is especially true with the rapid growth of the information technology (IT) profession and the academic programs in computing offered by colleges and universities. The dynamic growth of the IT profession provides a challenging and ongoing undertaking for college/university educators who are responsible for preparing both entry-level and experienced IT professionals for the workforce. One way to meet this challenge is to collect and analyze data from industry professionals concerning IT competencies. Once analyzed, the results can identify those competencies considered to be important or not important by IT professionals. If deemed important, the results can also indicate whether or not the competencies are critical as curricular offerings in IT higher education.

A number of previous studies have surveyed IT professionals to identify and evaluate the importance of various IT skills and knowledge areas that should be addressed in an IT curriculum. These studies have been useful in understanding how the needs of industry have changed over time; particularly with respect to technical skills. Hingorani and Sankar [5] compared the prioritization of IT skills by graduating seniors versus those by industry professionals. Jiang, Udeh, and Ayajneh [7] surveyed recruiters in reference to 13 different IT related job skills. Richards, Yellen, Kappelman, and Guynes [14] asked IT managers to rate the importance of 19 business, people-related, and technical skills. Bailey and Mitchell [1] focused their study on employers' perceptions of the importance of various "soft skills," while other 
researchers have analyzed the content of IT job advertisements in newspapers to determine the competencies that are considered to be the most essential by employers [10, 16, and12].

The objectives of this study are to answer the following questions:

1. What competencies in Information Technology are critical to workforce requirements for new hires/entry-level IT positions and current employees, as assessed by field professionals?

2. What competencies in Information Technology are usable to workforce requirements for new hires/entry-level IT positions and current employees, as assessed by field professionals?

3. What competencies in Information Technology are of no importance to workforce requirements for new hires/entry-level IT positions and current employees, as assessed by field professionals?

\section{RESEARCH APPROACH}

The current study surveyed information technology (IT) professionals who are employed by over 1,600 organizations in the Southwestern Pennsylvania region. The list of IT professionals used in the study was provided by the Pittsburgh Technology Council (PTC), the Association of Information Technology Professionals (AITP), and Corporate Education Career Services partners with Robert Morris University.

The geographic region involved in the study included five counties in and around the Pittsburgh area: Allegheny, Washington, Butler, Beaver, and Westmoreland. CorpTech (a Massachusettsbased survey organization) placed the Pittsburgh region as one of the nation's top ten cities for software job growth and high-tech job growth [2]. In the survey of 40,000 technology companies nationwide, Pittsburgh ranked near Cleveland and Cincinnati; cities that are similar to Pittsburgh in size and economic growth. Atlanta ranked first in the CorpTech study [2]. Pittsburgh also ranks high in information technology due to considerable advances in the region's healthcare information systems. The University of Pittsburgh Medical Center has been ranked among America's 100 Most Wired Hospitals for the past six years [4, 8]. The regional sample in the current study was intended to provide insight into the demand for IT skills in and around the Pittsburgh area. However, the findings of the study may be generalized to other geographic regions that are similar to the Pittsburgh region, in terms of demographics, economics, and maturity of information technology.

A questionnaire was developed based on a literature review and input from the PTC, the AITP, and the Corporate Education Career Services partners. The questionnaire, accompanied with a cover letter, was mailed during the period of February through May 2004. Two other information-refining phases were developed. In the first, follow-up calls and on site visits with approximately half of the original respondents were made to enhance the validity and response nature of the survey instrument. During this phase of the study, the researchers used an openended method to ascertain original findings. A second phase of post questionnaire analysis included lengthy, face-to-face IT management interviews with the original respondents. This phase of the study was commissioned by Robert Morris University to the Crossroads Development Group [3] as part of an institution-wide assessment plan. 
Statistically, of the 135 questionnaires mailed, 91 (67 percent) were returned. The returns of ten respondents were unusable because the respondents devoted insufficient time to IT activities or reported ambiguous data. The unusable responses reduced the number of usable returns from 91 to 81 ( 89 percent). The 81 returns became the basis for the analysis of data and are referred to as "the sample" for this study. The number of unique organizations/corporations surveyed in this sample was 70. In a few cases, those corporations having large and diverse IT departments (with multiple supervisors and managers in various departments or divisions) provided more than one response per corporate entity.

The design of the questionnaire included the following three main parts:

Part I Personal and Corporate Profile - This section was used to collect data about the experience, corporate hierarchical level, IT service, degrees attained and current professional status of the respondents.

Part II Areas of Study - This section was used to collect data concerning curriculum.

Part III Competency Profile - This section was developed to elicit information concerning the development of competencies associated with IT.

For the purpose of the present research, Parts I and III of the questionnaire were used.

\section{SAMPLE CHARACTERISTICS}

The first part of the questionnaire was designed to collect information regarding the general characteristics of the study sample $(n=81)$. An analysis of each question is presented in terms of frequency of response. The total population for this study included professionals who are involved with Information Technology in business, industrial, governmental, and service organizations in Southwestern Pennsylvania.

The two largest components of the sample were from the Education \& Health Services Industry (23.5\%) and Manufacturing (22.2\%), followed by Financial Activities, such as Banking and Insurance (18.5\%). Various other industries represented include Information Services, Transportation, Utilities, Business Services, Government, Retail and Construction.

More than one-half of the individual respondents (55.6\%) reported that they held a Master's Degree. The size of the respondents' employers ranged from five employees to 142,000 employees. The years of experience of the respondents was more evenly distributed, with the highest percentage occurring between five and ten years $(22.2 \%)$.

The functional roles of the respondents included IT Managers (29.6\%), Project Leaders (17.3\%) Programmer/Analysts (13.6\%), Systems Analysts (8.6\%), Network Administrators (6.2\%), Technical Support Personnel (6.2\%), and Database Administrators (4.9\%). An additional 11.1\% of the participants were assigned to an Other category and were included in the study because they did indicate time spent in the IT profession 


\section{ANALYSIS OF DATA AND FINDINGS}

Part III of the questionnaire asked the respondents to determine the specific IT Competencies that professionals consider critical, usable, or of no importance. The eight Competency groupings included were:

\section{Competency Grouping $\quad$ Composed of ...}

1. IT Fundamentals

2. Web and Multimedia

3. Systems Architecture

4. Management

5. Software

6. Database

7. Systems Development

8. Professional integration personal productivity software skills, information systems fundamentals, discrete math web authoring skills, graphics/multimedia skills, e-business concepts and technologies network design, operating systems concepts, security personnel supervision, managing IT projects, production scheduling, and IT managerial skills introductory and advanced programming skills, and objectoriented programming skills database modeling and programming, and database application development

SDLC concepts, SDLC methodologies, and object-oriented systems development methodologies

Written/oral communication, professional ethics, team work, problem solving, and time management

These data were analyzed by calculating mean values for each IT Competency Grouping, based on the following scale: $0=$ no importance $; 1=$ usable; and $2=$ critical .

Table 1. Comparison of Respondents' Perceived Importance of IT Competencies as Related to New Hires/Entry-level

\begin{tabular}{lllllll}
\hline Competency & \multicolumn{2}{l}{ No Importance } & Usable & \multicolumn{2}{c}{ Critical } \\
& $\mathrm{n}$ & $\%$ & $\mathrm{n}$ & $\%$ & $\mathrm{n}$ & $\%$ \\
\hline Professional (non-technical) & 0.0 & 0.0 & 17.0 & 21.0 & 64.0 & 79.0 \\
Database & 9.0 & 11.1 & 39.0 & 48.1 & 33.0 & 40.7 \\
Software Development & 13.0 & 16.6 & 49.0 & 60.5 & 19.0 & 23.5 \\
Systems Architecture & 10.0 & 12.3 & 52.0 & 64.2 & 19.0 & 23.5 \\
Systems Development & 10.0 & 12.3 & 55.0 & 67.9 & 16.0 & 19.8 \\
Web and Multimedia & 13.0 & 16.0 & 54.0 & 66.7 & 14.0 & 17.3 \\
Management & 19.0 & 23.5 & 51.0 & 63.0 & 11.0 & 13.6 \\
IT Fundamentals & 2.0 & 2.5 & 70.0 & 86.4 & 9.0 & 11.1 \\
\hline
\end{tabular}

A review of Table 1 reveals that the respondents deemed the Professional (non-technical) competency to be important with the highest ranking of critical (79\%). The Professional competency grouping included written and oral communications, professional ethics, teamwork, 
problem solving, and time management. IT Fundamentals was ranked second in level of importance with a response rate of $97.5 \%$. Although IT Fundamentals was the least critical competency (11.1\%), it was found to be the most usable by 86.4 percent of the sample. With respect to IT Fundamentals, similar results were obtained from the Crossroads Development Group survey, in which Discrete Math was found to be the least critical competency despite the highest ranking of Robert Morris University graduates when compared to graduates from other institutions in Western Pennsylvania.

Table 2. Comparison of Respondents' Perceived Importance of IT Competencies as Related to Current Employees

\begin{tabular}{lllllll}
\hline Competency & \multicolumn{2}{c}{ No Importance } & \multicolumn{2}{c}{ Usable } & \multicolumn{3}{c}{ Critical } \\
& $\mathrm{n}$ & $\%$ & $\mathrm{n}$ & $\%$ & $\mathrm{n}$ & $\%$ \\
\hline Professional (non-technical) & 0.0 & 0.0 & 10.0 & 12.3 & 71.0 & 87.7 \\
Database & 10.0 & 12.3 & 28 & 34.6 & 43.0 & 53.1 \\
Software Development & 13.0 & 16.6 & 39.0 & 48.1 & 29.0 & 35.8 \\
Systems Development & 11.0 & 13.6 & 41.0 & 50.6 & 29.0 & 35.8 \\
Systems Architecture & 10.0 & 12.3 & 44.0 & 54.3 & 27.0 & 33.3 \\
Web and Multimedia & 11.0 & 13.6 & 48.0 & 59.3 & 22.0 & 27.2 \\
Management & 4.0 & 4.9 & 56.0 & 69.1 & 21.0 & 25.9 \\
IT Fundamentals & 1.0 & 1.2 & 65.0 & 80.3 & 15.0 & 18.5 \\
\hline
\end{tabular}

A review of Table 2 reveals that the respondents deemed the Professional (non-technical) competency to be important with the highest ranking of critical $(87.7 \%)$. This finding is congruent with the findings in Table 1 for new hires/ entry-level positions. Again, second in level of importance with a response rate of $98.8 \%$ was the competency area of IT Fundamentals. Although IT Fundamentals was the least critical competency (18.5\%), it was found to be most usable by $80.3 \%$ of the respondents. Interestingly, nearly every competency found critical for new hires/entry-level was also found critical for current employees. The only differences in the order of rankings involved the Software Development and Systems Architecture competences. Additionally, over half of the respondents indicated Database competencies (53.1\%) to be critical for current employees as opposed to 40.7 percent for new hires/entry-level. IT Fundamentals was the least critical competency (18.5\%) but also the most usable $(80.2 \%)$.

\section{CONCLUSION}

This study obtained input from IT professionals concerning IT competencies. The competencies were directly related to the curriculum requirements specified in the ABET-CAC accreditation standards for information systems degree programs. The IT professionals were asked to rank eight categories of competencies by level of importance and by level of criticality.

Not only did all of the respondents rate Professional (non-technical) competencies as being important, they ranked it the most critical for both entry-level/new hires as well as for current employees. The results of the current study are consistent with those of Richards et al. [14] and Van Slyke [17], in which the researchers found that employers tend to rate professional, nontechnical skills higher than technical skills. These results may be explained by the nature of IT 
positions: the requirements of IT positions tend to be specific for each position. For example, competencies in software development, such as programming skills, may be critical for programmers, but less important for network administrators or IT managers. By contrast, professional competencies such as oral and written communications, professional ethics, and problem solving are more general and may apply to virtually all IT positions. Based on this finding, it is important for IT faculty to emphasize written/oral communications, professional ethics, team work, problem solving, and time management within the curriculum. These competencies should be emphasized in the curriculum, despite the tendency for some students to underestimate their importance.

Further, the survey revealed that IT Fundamentals, which included personal productivity software skills, information systems fundamentals, and discrete math as the second most important competency area for both entry-level/new hires and current employees as well. The two follow-up, fact-finding activities revealed two findings that were tightly coupled to the original survey results: First, many of the respondents indicated little or no need for discrete math, despite a recognized highest level of mastery by Robert Morris University information systems graduates. Second, the results revealed that there is a critical need for personal productivity software skills for all information systems professionals.

With respect to the competency areas deemed no importance, the results for the two focus groups were not as symmetrical. For entry-level/new hires, Management $(23.5 \%)$ had the highest ranking of no importance for new hires/ entry-level employees; and Software Development $(16.6 \%)$ had the highest ranking of no importance for current employees. The second and third competency areas deemed no importance for entry-level/new hires were Software Development $(16.6 \%)$ and Web and Multimedia (16.0\%). Systems Development (13.6\%) and Web and Multimedia (13.6\%) were second and third, respectively, for current employees.

The no importance response rate regarding the Management competency for entry-level/new hires was not unexpected with respect to how management was defined in the survey instrument to include aspects such as supervising personnel, managing IT projects, and production scheduling. These activities are not normally associated with entry level positions. Similarly, Software Development was defined to include advanced programming skills, which many IT professionals feel may only be acquired via extended work experience.

As previously discussed, the technical competency requirements for IT positions are diverse. This diversity is a possible factor as to why the competency areas of Database, Software Development, Systems Development, Systems Architecture, and Web and Multimedia all had a similar determination of no importance and fell in a similar $12.3 \%$ to $16.6 \%$ range.

In an effort to prepare graduates, colleges and universities should continue to partner with IT professionals in order to recognize those competencies that are deemed most critical in the workplace. The most responsive, receptive, and noteworthy IT degree programs will be the programs that best prepare graduates for the IT workforce of today and tomorrow. 


\section{REFERENCES}

1. Bailey, J., \& Mitchell, R. B. (2000, March). Developing problem solving skills of IS professionals. Decision Sciences Institute Southwestern Region Proceedings, 156-158.

2. Creedy, S. (1995, August 22). High-tech poll high on city: Pittsburgh rates well in software job growth. Pittsburgh Post-Gazette, p. B7.

3. Crossroads Development Group (2004). University information technology program evaluation. Robert Morris University Executive Summary.

4. Guzzo, M. (2003). Committed to IT. Pittsburgh Business Times, 23(2), 21.

5. Hingorani, K., \& Sankar, C. S. (1995). Entry level MIS jobs: Industry expectations versus academic preparation. Journal of Computer Information Systems, (Spring, 1995), 18-27.

6. IS 2002 model curriculum and guidelines for undergraduate programs in information systems. (2002). Retrieved June 8, 2004, from IS 2002 Web Site: http://www.aisnet.org/curriculum/

7. Jiang, J., Udeh, I., \& Hayajneh, A. (1994). Employers' expectations of incoming graduates: From recruiters' views. Journal of Computer Information Systems, (Spring, 1994), 57-59.

8. Landro, L. (2002, June 10). Who leads the online race: A look at the hospitals that are out in front in the drive to bring information technology to healthcare. The Wall Street Journal, p. R7.

9. Lee, D., Trauth, E., \& Farwell, D. (1995). Critical skills and knowledge requirements of IS professionals: A joint academic/industry investigation. MIS Quarterly, 19(3), 313-340.

10. Maier, J. L., Clark, W. J., \& Remington, W. J. (1998). A longitudinal study of the management information systems (MIS) job market. Journal of Computer Information Systems, (Fall 1998), 37-42.

11. McGee, M. (1996, August 19). Soft skills can boost careers. Information Week, p. 84.

12. Modzelewski, E. (2001, June 27). Tech jobs go begging for lack of workers in area. Pittsburgh Post-Gazette, p. C1.

13. Paytas, J. (2001, December). Southwestern Pennsylvania industry executive summary: Southwestern Pennsylvania industrial cluster analysis. Pittsburgh Technology Council.

14. Richards, T., Yellen, R., Kappelman, L., \& Guynes, S. (1998). Information managers' perceptions of IS job skills. Journal of Computer Information Systems, 38(3), 53-57.

15. Smith, D. F., et al. (2001, December). The education needs: Southwestern Pennsylvania industry cluster analysis. Pittsburgh Technology Council..

16. Todd, P., McKeen, J., \& Gallupe, R. B. (1995). The evolution of IS job skills: A content analysis of IS job advertisements from 1970 to 1990. MIS Quarterly, 19(1), 1-27.

17. Van Slyke, C., Ketter, J., \& Cheney, P. (1998). Skill Requirements for Entry-level IS Graduates:A Report from Industry. Journal of Computer Information Systems, 38(3), 6-10. 